\title{
Identification of an intracellular metabolic signature impairing beta cell function in the rat beta cell line INS-1E and human islets
}

\author{
I. Goehring • N. S. Sauter • G. Catchpole • A. Assmann • \\ L. Shu • K. S. Zien • M. Moehlig • A. F. H. Pfeiffer • \\ J. Oberholzer $\cdot$ L. Willmitzer $\cdot$ J. Spranger $\cdot$ K. Maedler
}

Received: 14 December 2010 / Accepted: 6 June 2011 /Published online: 28 July 2011

(C) Springer-Verlag 2011

\begin{abstract}
Aims/hypothesis Chronic hyperglycaemia promotes the progressive failure of pancreatic beta cells in patients with type 2 diabetes mellitus, a clinically highly relevant phenomenon known as glucotoxicity. The intracellular metabolic consequences of a chronically high availability of glucose in beta cells are, as yet, poorly understood in its full complexity.

Methods An unbiased metabolite profiling analysis (GCtime-of-flight-MS) was used to identify the time course of core metabolite patterns in rat beta cell line INS-1E during exposure to high glucose concentrations and its relation to insulin expression.

Results We report here that pentose phosphate pathway (PPP) metabolites accumulate remarkably during chronic but not acute glucose treatment, indicating altered process-
\end{abstract}

I. Goehring, N. S. Sauter, J. Spranger and K. Maedler contributed equally to the study.

Electronic supplementary material The online version of this article (doi:10.1007/s00125-011-2249-7) contains peer-reviewed but unedited supplementary material, which is available to authorised users.

I. Goehring • A. Assmann · M. Moehlig • A. F. H. Pfeiffer •

J. Spranger

Department of Endocrinology, Diabetes and Nutrition,

Charité-Universitaetsmedizin Berlin,

Nuthetal, Germany

I. Goehring • A. Assmann • M. Moehlig - A. F. H. Pfeiffer •

J. Spranger

Department of Clinical Nutrition,

German Institute of Human Nutrition Potsdam-Rehbruecke,

Nuthetal, Germany

N. S. Sauter

Department of Biomedicine, University Hospital Basel,

Basel, Switzerland ing of glucose through the pentose phosphate pathway. Subsequent functional studies in INS-1E cells and human islets revealed that a disturbance in this pathway contributes to decreases in insulin gene expression and a lack of glucose-stimulated insulin secretion. These effects were found to depend on the activation of extracellular-regulatedkinase (ERK1/2). Long-term inhibition of 6-phosphogluconic acid dehydrogenase resulted in accumulation of PPP metabolites, induced ERK1/2 activation independently of high glucose and impaired beta cell function. In turn, inhibition of ERK1/2 overstimulation during chronic glucose exposure partly inhibited metabolite accumulation and restored beta cell function.

Conclusions/interpretation Based on unbiased metabolite analyses, the data presented here provide novel targets, namely the inhibition of PPP metabolite accumulation

G. Catchpole $\cdot$ L. Willmitzer

Max Planck Institute of Molecular Plant Physiology,

Potsdam-Golm, Germany

J. Oberholzer

Division of Transplantation, University of Illinois at Chicago,

Chicago, IL, USA

L. Shu $\cdot$ K. S. Zien $\cdot$ K. Maedler $(\bowtie)$

Islet Biology Laboratory, Centre for Biomolecular Interactions

Bremen, University of Bremen,

Leobener Straße NW2, Room B2080,

28359 Bremen, Germany

e-mail:kmaedler@uni-bremen.de 
towards the therapeutic goal to preserve and potentially improve beta cell function in diabetes.

Keywords Beta cell $\cdot$ Diabetes $\cdot$ Extracellular-regulated protein kinase - Glucotoxicity - Metabolite profiling .

Pentose phosphate pathway

$\begin{array}{ll}\text { Abbreviations } \\ \text { 6-AN } & \text { 6-Aminonicotinamide } \\ \text { BETA2 } & \text { Beta cell E-box transactivator 2 } \\ \text { ERK } & \text { Extracellular signal-regulated protein kinase } \\ \text { MAFA } & \begin{array}{l}\text { v-Maf musculoaponeurotic fibrosarcoma } \\ \text { oncogene homolog A (avian) }\end{array} \\ \text { PC } & \text { Principal component } \\ \text { PCA } & \text { Principal component analysis } \\ \text { PDX-1 } & \text { Pancreatic and duodenal homeobox 1 } \\ \text { 6PGD } & \text { 6-Phosphogluconate dehydrogenase } \\ \text { PPP } & \text { Pentose phosphate pathway } \\ \text { ROS } & \text { Reactive oxygen species } \\ \text { si } & \text { Small interfering } \\ \text { TCA } & \text { Tricarboxylic acid } \\ \text { TOF } & \text { Time of flight }\end{array}$

\section{Introduction}

The current epidemic increase in the incidence of type 2 diabetes mellitus is a major challenge of global health. Impaired beta cell function and survival are major components in this development, but also in the progressive deterioration of type 2 diabetes. Glucose is a key modulator of beta cell function and survival that regulates an array of cellular signalling networks. Chronically elevated glucose leads to beta cell desensitisation and glucotoxicity, affecting beta cell function on both secretory and expression levels $[1,2]$. Hyperglycaemia-induced beta cell dysfunction is associated with the downregulation of key islet genes and transcription factors (e.g. insulin, $P D X-1$ [also known as $P D X 1], M A F A$ ) concomitant with a marked upregulation of several suppressed factors (e.g. lactate dehydrogenase A, hexokinase, IL-1 $\beta$, reactive oxygen species [ROS]) [3-6]. While short-term glucose stimulation promotes insulin transcription, chronic exposure to high glucose impairs insulin gene expression [7]. The precise mechanism behind this phenomenon remains to be elucidated despite eminent clinical relevance in patients with type 2 diabetes, who regularly experience a progressive deterioration of glucose control and beta cell function.

Besides the genome, transcriptome and proteome of a tissue, a metabolic profile can give an instantaneous snapshot of cellular physiology as metabolites are intermediates or endproducts of metabolic events and various metabolites have been reported to act as second messengers modifying functionality of the cell. To identify potential novel mediators of insulin gene suppression via long-term high glucose treatment, an unbiased time course analysis of metabolites was performed in rat pancreatic INS-1E beta cells. We report here that pentose phosphate pathway (PPP) metabolites accumulate remarkably during chronic but not acute glucose treatment. Functional studies in INS-1E cells and human islets confirm that a disturbance in the PPP contributes to beta cell dysfunction, acting through ERK activation.

\section{Methods}

Islet isolation and cell culture Human islets were isolated from eight donors at the University of Illinois at Chicago as previously described by Oberholzer et al. [8]. After $24 \mathrm{~h}$ preculture, islets were exposed to CMRL-1066 culture medium containing $5.5,11.1$ or $33.3 \mathrm{mmol} / \mathrm{l}$ glucose with or without the addition of $10 \mu \mathrm{mol} / 1$ PD98059 (Calbiochem, La Jolla, CA, USA), $1 \mu \mathrm{mol} / 1 \mathrm{UO} 126$ (Calbiochem), $500 \mu \mathrm{mol} / 1$ 6-aminonicotinamide (6-AN; Sigma, Munich, Germany), $200 \mu \mathrm{mol} / 1$ diazoxide (Sigma, Munich, Germany) or $50 \mathrm{nmol} / 1$ somatostatin (Bachem, Bubendorf, Switzerland) for $72 \mathrm{~h}$. INS-1E cells were kindly provided by C. B. Wollheim, Geneva, Switzerland. Cells were pre-cultured in RPMI 1640 medium containing $3 \mathrm{mmol} / \mathrm{l}$ glucose for $24 \mathrm{~h}$ [9] before exposure to $3 \mathrm{mmol} / \mathrm{l}$ and $16 \mathrm{mmol} / \mathrm{l}$ glucose \pm inhibitors (PD98059 or 6-AN) for the indicated time periods. $\left[{ }^{12} \mathrm{C}_{6}\right]$ glucose was replaced by uniformly isotope-labelled $\left[{ }^{13} \mathrm{C}_{6}\right]$ glucose (Sigma) to confirm origination of metabolites from glucose metabolism.

RNA interference Small interfering (si)RNA-Lipofectamine2000 complexes were prepared according to the manufacturer's instructions (Lipofectamine2000 obtained from Invitrogen, Karlsruhe, Germany, see electronic supplementary material $[\mathrm{ESM}]$ for details).

Metabolite extraction and GC-time of flight (TOF)-MS measurements Metabolite profiling was performed on a Leco Pegasus 3 TOF mass spectrometer (Leco, St Joseph, MI, USA) equipped with a direct thermal desorption injector (ATAS GL) coupled to an HP 5890 gas chromatograph and a dual-arm autosampler with automatic derivatisation and liner exchange, chromatograms were processed using Leco ChromaTOF software (version 3.25) and principal component analysis (PCA) was performed with MATLAB 7.0 (Mathworks, Ismaning, Germany; see ESM for details).

RNA expression analysis Total RNA of isolated islets was extracted after overnight culture as described previously by 
Maedler et al. [5]. For quantitative analysis, we used the LightCycler Quantitative PCR System (Roche, Mannheim, Germany) with a commercial kit (LightCycler FastStart DNA Master plus SYBR Green I; Roche). Comparison of the target data with $\alpha$-tubulin and $\beta$ actin showed similar results. Total RNA from INS-1E cells was isolated using Trizol reagent (Invitrogen) according to the manufacturer's protocol. One-step real-time PCR was carried out using the 7900 HT Sequence Detection System (Applied Biosystems, Darmstadt, Germany) with SYBR Green Mastermix (Qiagen, Hilden, Germany) or TaqMan primer/probes (6PGD [also known as $P G D], \beta$-actin; Applied Biosystems). For the primers, see ESM.

Western blot analysis Islets were lysed as described by Ardestani et al. [10]. Membranes were incubated with rabbit anti-phospho-44/42 MAP-kinase (Thr202/Tyr204), anti-6-phosphogluconate dehydrogenase (6PGD) (Abcam, Cambridge, UK) and anti-actin antibodies (Cell Signaling, Beverly, MA, USA) overnight at $4^{\circ} \mathrm{C}$ followed by incubation with horseradish-peroxidase-linked anti-rabbit IgG (Jackson, Newmarket, UK).

Glucose-stimulated insulin secretion For acute insulin release in response to glucose, islets were washed for $30 \mathrm{~min}$ in KRB containing $2.8 \mathrm{mmol} / \mathrm{l}$ glucose and $0.5 \%$ BSA. KRB was then replaced by KRB with $2.8 \mathrm{mmol} / 1$ glucose (basal) or by KRB with $16.7 \mathrm{mmol} / \mathrm{l}$ glucose (stimulated) for $60 \mathrm{~min}$. Supernatant fractions were analysed by human insulin ELISA (Alpco, Salem, SH, USA).

\section{Results}

Reduced insulin and transcription factor gene expression due to chronic high glucose Insulin mRNA levels were examined in response to elevated glucose levels in INS-1E cells and human isolated islets over time periods of 48 and $96 \mathrm{~h}$, respectively. While insulin mRNA was unchanged in INS-1E (Fig. 1a) cells over a time period of $8 \mathrm{~h}$ and human islets at $1 \mathrm{~h}$ (Fig. 1b), chronic exposure to high glucose reduced insulin transcription levels after 24 and 48 h by $55 \%$ and $64 \%$, respectively, compared with low glucose in INS-1E cells (Fig. 1a) and by $43 \%$ and $39 \%$ (Fig. 1b, $p<0.01$ ) in human islets after 72 and $96 \mathrm{~h}$, respectively. These differences were mirrored by significantly reduced mRNA levels of the transcription factors $\mathrm{v}$ maf musculoaponeurotic fibrosarcoma oncogene homolog A (avian) (Mafa), beta cell E-box transactivator 2 (Beta2 [also known as Neurod1]) and pancreatic and duodenal homeobox $1(P d x-1)$ in INS-1E cells after $48 \mathrm{~h}$ (Fig. 1c, $p<0.05)$ and of MAFA and $P D X-1$, which are key regulators of insulin transcription, in human islets after 96 h (Fig. 1d, $p<0.05$ ).

Accumulation of metabolites of the PPP during chronic glucose exposure contributes to reduced insulin expression To identify potential mediators of insulin gene suppression via long-term high glucose treatment, an unbiased time course analysis of metabolites was performed in INS-1E cells, during which 73 metabolites were uniquely identified (ESM Table 1). PCA was performed on the data obtained to illustrate the disparity between both the time points and the applied glucose concentrations on the metabolite level
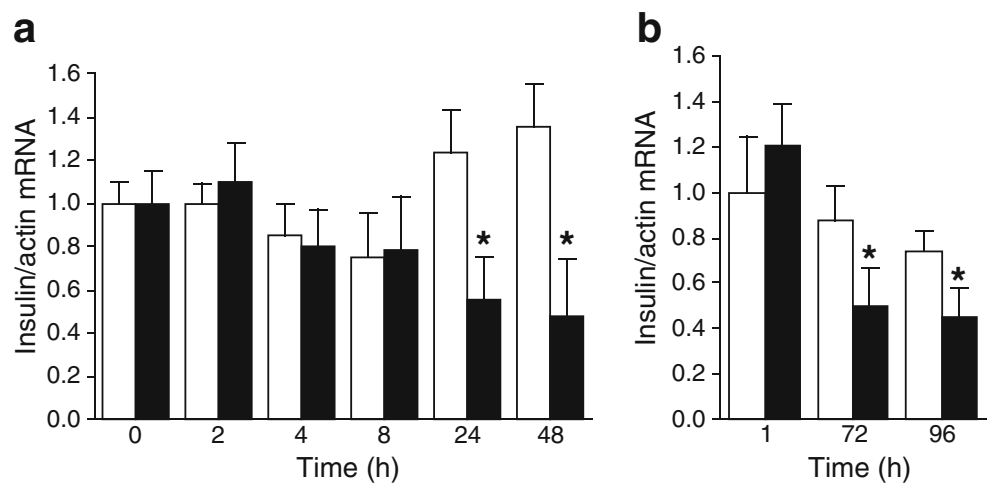
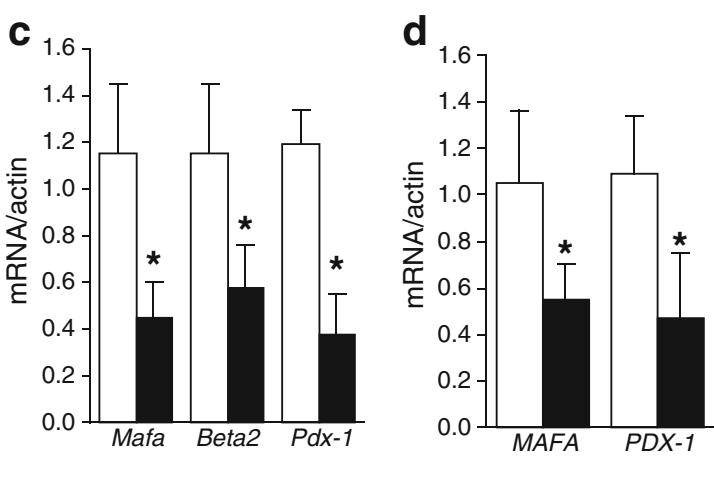

Fig. 1 The duration of exposure to high glucose levels is most critical for maintaining insulin gene expression. INS-1E cells were exposed to $3 \mathrm{mmol} / \mathrm{l}$ and $16 \mathrm{mmol} / \mathrm{l}$ glucose during $48 \mathrm{~h} \mathrm{(a,c)} \mathrm{and} \mathrm{human} \mathrm{islets} \mathrm{to}$ 5.5 and $22.2 \mathrm{mmol} / 1$ glucose during $96 \mathrm{~h}(\mathbf{b}, \mathbf{d})$ of culture. Quantitative RT-PCR analysis of insulin $(\mathbf{a}, \mathbf{b})$ and of the transcription factors Mafa, Beta 2 and $P d x-1$ after $48 \mathrm{~h}$ (c) or MAFA and $P D X-1$ after $72 \mathrm{~h}(\mathbf{d})$. Mean expression levels are normalised to control (low glucose) and to actin and tubulin with the same result. Data shown are means \pm SE from three different experiments (INS-1E and islets) from three different islet donors. ${ }^{*} p<0.05$ high glucose compared with low glucose, same time point. a, c White bars, $3 \mathrm{mmol} / \mathrm{l}$ glucose; black bars, $16 \mathrm{mmol} / 1$ glucose. b, d White bars, $5.5 \mathrm{mmol} / 1$ glucose; black bars, $22.2 \mathrm{mmol} / \mathrm{l}$ glucose 
(Fig. 2a). Principal component (PC)1 alone accounted for $91.4 \%$ of the total variance contained within the dataset and was able to resolve both time series and glucose treatments. This therefore renders PC2, which only accounts for $6.2 \%$, and all subsequent components of only relatively minor relevance. In Fig. 2a, high glucose treated cells can already be discriminated from low glucose counterparts 5 min after treatment. Prolonged exposure to high glucose caused clear differentiation compared with early time points, thus demonstrating the differential impact of acute and chronic glucose exposure on the beta cell. Only those metabolites that are differentially regulated are shown in Table 1 . These data are consistent with the accumulation of glucose metabolic intermediates in several pathways, as observed under chronic high glucose conditions in INS-1 832/13 cells [11]. The most important metabolites driving the separation from acute to
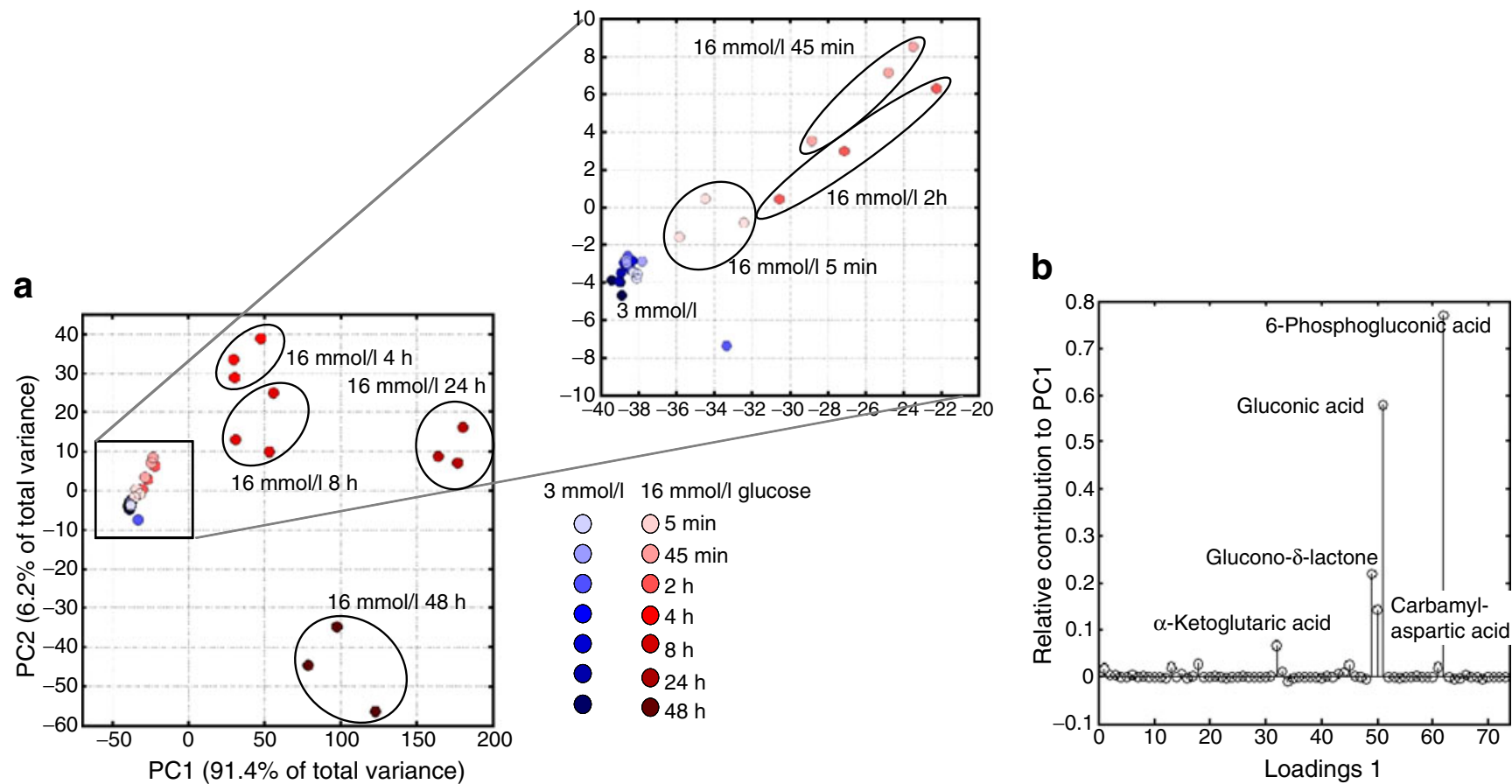

C

$3 \mathrm{mmol} / \mathrm{glc} 48 \mathrm{~h}$ $3 \mathrm{mmol} / \mathrm{l} \mathrm{glc}+6-\mathrm{AN} 48 \mathrm{~h}$

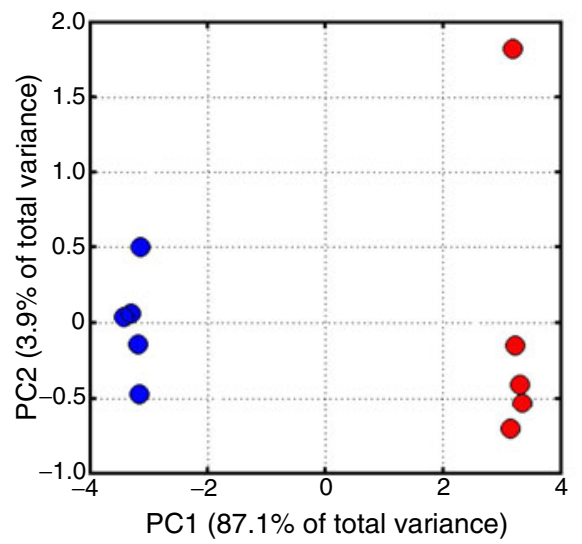

d

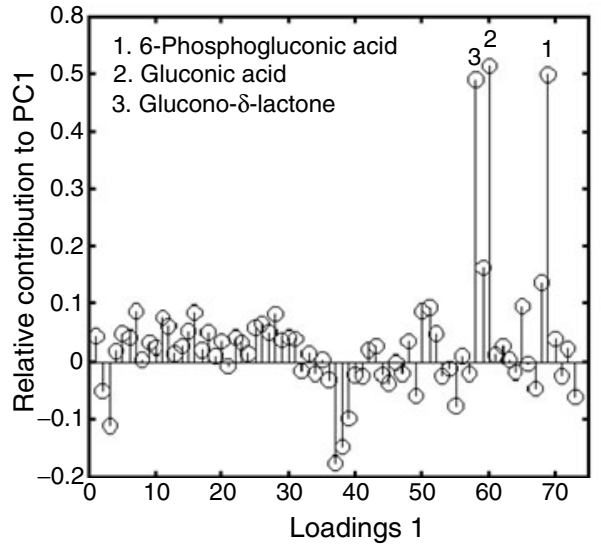

Fig. 2 Metabolites of the PPP drive differences in the metabolic intracellular patterns of INS-1E cells acutely and chronically treated with low ( $3 \mathrm{mmol} / \mathrm{l}$, blue circles) and high $(16 \mathrm{mmol} / \mathrm{l}$ red circles $)$ glucose. PCA score plots (a) illustrate separation of samples according to culture conditions and exposure time. Each data point represents the entire metabolite profile of a sample. Loading plot (b) describes the contribution of each metabolite to PC1. The PPP metabolites glucono$\delta$-lactone, 6-phosphogluconic acid and gluconic acid, the pyrimidine pathway intermediate carbamyl-aspartic acid and the TCA cycle intermediate $\alpha$-ketoglutaric acid were the most dominant factors driving the observed separation. Colour intensity of circles relates to duration of exposure, with lightest dots corresponding to $5 \mathrm{~min}$ and darkest to $48 \mathrm{~h}$. c PCA score plot illustrates separation of INS-1E treated with $3 \mathrm{mmol} / 1$ glucose (glc) (blue) and $3 \mathrm{mmol} / \mathrm{l}$ glucose + $100 \mu \mathrm{mol} / \mathrm{l} 6$-AN (red) for $48 \mathrm{~h}$ (data were log-transformed prior to PCA). Loading plot (d) describes the contribution of each metabolite to PC1. The PPP metabolites glucono- $\delta$-lactone, 6-phosphogluconic acid and gluconic acid were driving the observed separation. Representative plots are shown from three $(\mathbf{a}, \mathbf{b})$ and five $(\mathbf{c}, \mathbf{d})$ independent experiments 
Table 1 Identified metabolites differentially regulated in INS-1E under high vs. low glucose conditions after short-term $(45 \mathrm{~min})$ and chronic incubation $(48 \mathrm{~h})$. Presented are the relative metabolite median fold changes between $3 \mathrm{mmol} / \mathrm{l}$ and $16 \mathrm{mmol} / 1$ glucose $(n=3$ in each condition) from two independent time course experiments. Origination of measured metabolites from glucose metabolism was determined by [13C] glucose labeling and those metabolites successfully traced are marked with "a".

\begin{tabular}{|c|c|c|}
\hline \multirow[t]{3}{*}{ Metabolite } & \multicolumn{2}{|c|}{$\begin{array}{l}\text { Median fold change } \\
\text { at } 16 \text { vs. } 3 \mathrm{mmol} / 1 \text { glucose }\end{array}$} \\
\hline & \multicolumn{2}{|c|}{ Incubation time } \\
\hline & $45 \mathrm{~min}$ & $48 \mathrm{~h}$ \\
\hline Glucose $^{\mathrm{a}}$ & +4.1 & +5.0 \\
\hline \multicolumn{3}{|l|}{ Glycolysis } \\
\hline Glucose 6-phosphate $^{\mathrm{a}}$ & +3.9 & +10.9 \\
\hline Fructose 1,6 -bisphosphate $^{\mathrm{a}}$ & +2.7 & +2.5 \\
\hline Glycerate 3-phosphate $^{\mathrm{a}}$ & +3.7 & +3.1 \\
\hline Phospho(enol)pyruvic acid ${ }^{\mathrm{a}}$ & +2.7 & +3.0 \\
\hline Pyruvic acid ${ }^{\mathrm{a}}$ & +3.6 & +30.1 \\
\hline 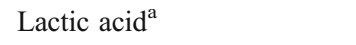 & +2.5 & +7.3 \\
\hline \multicolumn{3}{|l|}{ Krebs cycle } \\
\hline Citric acid $^{\mathrm{a}}$ & +2.0 & +9.9 \\
\hline$\alpha$-Ketoglutaric acid $^{\mathrm{a}}$ & - & +28.6 \\
\hline Succinic acid $^{\mathrm{a}}$ & +2.3 & +13.5 \\
\hline Fumaric $\operatorname{acid}^{\mathrm{a}}$ & +2.5 & +4.8 \\
\hline Malic acid ${ }^{\mathrm{a}}$ & +4.4 & +22.7 \\
\hline \multicolumn{3}{|l|}{ Polyol synthesis } \\
\hline Sorbitol $^{\mathrm{a}}$ & - & +2.0 \\
\hline Fructose $^{\mathrm{a}}$ & - & +2.1 \\
\hline \multicolumn{3}{|l|}{ PPP } \\
\hline Gluconic acid- $\delta$-lactone $^{\mathrm{a}}$ & +3.4 & +91.8 \\
\hline Gluconic acid ${ }^{\mathrm{a}}$ & - & +249.3 \\
\hline 6-Phosphogluconic acid ${ }^{\mathrm{a}}$ & +10.7 & +330.1 \\
\hline Ribose 5-phosphate ${ }^{\mathrm{a}}$ & - & +2.0 \\
\hline \multicolumn{3}{|l|}{ Glycerol synthesis } \\
\hline Glycerol $^{\mathrm{a}}$ & - & +4.8 \\
\hline \multicolumn{3}{|l|}{ DNA/RNA synthesis } \\
\hline Carbamyl-aspartic acid ${ }^{\mathrm{a}}$ & - & +305.8 \\
\hline \multicolumn{3}{|l|}{ GABA synthesis } \\
\hline$\gamma$-Aminobutyric acid ${ }^{\mathrm{a}}$ & - & +2.0 \\
\hline \multicolumn{3}{|l|}{ Polyamine synthesis } \\
\hline Ornithine & - & -2.0 \\
\hline Putrescine & - & +3.9 \\
\hline
\end{tabular}

chronic glucose were gluconic acid, glucono- $\delta$-lactone and 6-phosphogluconic acid (Fig. 2b), metabolites of the PPP, carbamyl-aspartic acid from pyrimidine synthesis and $\alpha$ ketoglutaric acid from the tricarboxylic acid (TCA) cycle.

We further investigated whether inhibition of the PPP following 6-phosphogluconic acid formation has an effect on insulin gene transcription and secretion. The addition of 6-AN, a potent inhibitor of 6-phosphogluconic acid dehydrogenase $[12,13]$, to $3 \mathrm{mmol} / 1$ glucose-treated cells for $48 \mathrm{~h}$ also promoted accumulation of those PPP metabolites, thus mediating the metabolic state of the beta cells under high glucose conditions and also demonstrating the specificity of the chemical inhibitor (Fig. 2c,d).

PCA was performed on data obtained from INS-1E cells cultured with $3 \mathrm{mmol} / 1$ glucose in the presence and absence of $100 \mu \mathrm{mol} / 1 \mathrm{6}$-AN. Indeed, low glucose treated samples could be clearly differentiated from those treated concomitantly with 6-AN (Fig. 2d). The PC loadings (Fig. 2d) demonstrate that the PPP metabolites 6-phosphogluconic acid, glucono- $\delta$-lactone and gluconic acid drove the separation. In addition, the results of the metabolite analysis indicate metabolism of glucose through the PPP even under low glucose conditions. The origination of the PPP metabolites from glucose metabolism, especially gluconic acid, which has been seldom reported in mammalian cells $[14,15]$, was demonstrated by $\left[{ }^{13} \mathrm{C}_{6}\right]$ glucose tracer experiments (ESM Figs 1-4).

Analysis of insulin mRNA levels in INS-1E cells (Fig. 3a) and in human islets (Fig. 3b) revealed that the inhibition of 6PGD and the accompanied rise in PPP metabolites indeed led to a significant decrease of insulin gene expression compared with low glucose alone, similarly to exposure to chronic high glucose. When human islets were exposed over 3 days to elevated glucose or 6-AN, glucose-stimulated insulin secretion was abolished. The reduction in glucose-stimulated insulin secretion was dose dependent (Fig. 3c).

A second set of experiments tested whether genetic inhibition of $6 P G D$ using siRNA interference would have similar effects. Human islets plated on extracellular matrix were transfected with $100 \mathrm{nmol} / 1$ siRNA to $6 P G D$ (a set of four different siRNA sequences was used) for 4 days at 5.5 or $22.2 \mathrm{mmol} / \mathrm{l}$ glucose, which resulted in a $53 \%$ reduction of $6 P G D$ mRNA (Fig. 3f). Similar to 6-AN exposure, glucose-stimulated insulin secretion was impaired at $5.5 \mathrm{mmol} / \mathrm{l}$ glucose and further impaired at $22.2 \mathrm{mmol} / \mathrm{l}$ glucose (Fig. 3d,e). Chronic glucose exposure ( $22.2 \mathrm{mmol} / \mathrm{l})$ inhibited glucose-stimulated insulin secretion (77\% reduction of stimulatory index vs $5.5 \mathrm{mmol} / \mathrm{l}$ glucose). Stimulatory index was $25 \%$ reduced by $6 P G D$ siRNA vs scramble siRNA at $5.5 \mathrm{mmol} / \mathrm{l}$ glucose $(p<0.05$, Fig. $3 \mathrm{~d})$ and further impaired at $22.2 \mathrm{mmol} / \mathrm{l}$ glucose $(30 \%$ reduced vs scramble siRNA at $22.2 \mathrm{mmol} / \mathrm{l}$ glucose, $p<0.05$, Fig. $3 \mathrm{e}$ ).

In contrast, chronic glucose exposure up to $96 \mathrm{~h}$ did not change expression levels of $6 P G D$. Glucose-induced regulation of $6 P G D$ mRNA or $6 \mathrm{PGD}$ protein level was not detected in either INS-1E cells (ESM Fig. 5a,b) or human islets (ESM Fig. 5c-e), while insulin mRNA was reduced in the same experiments (not shown). 


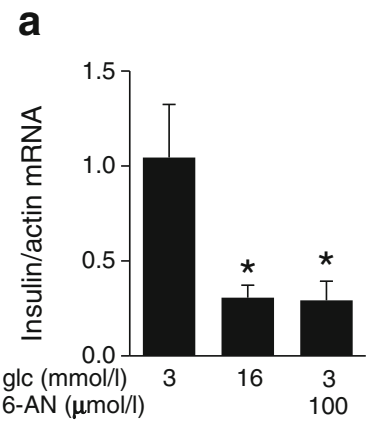

d

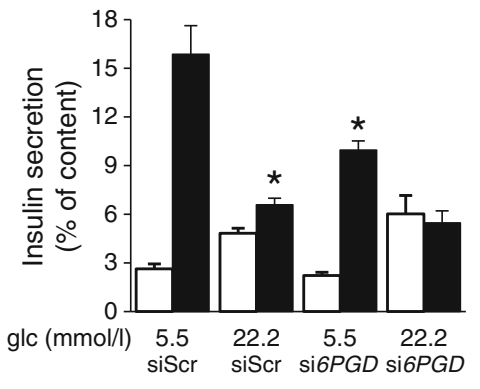

b

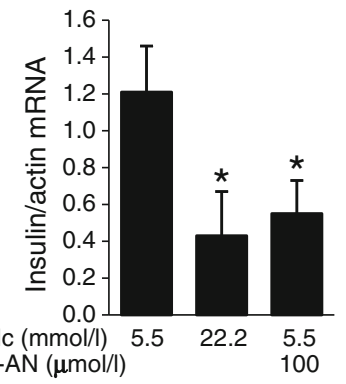

e

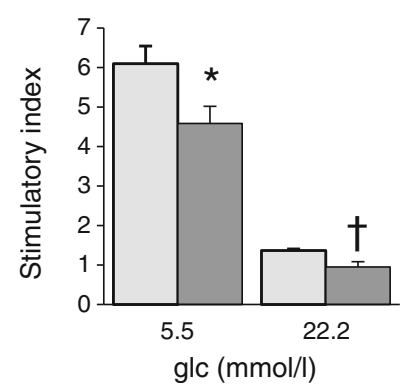

C

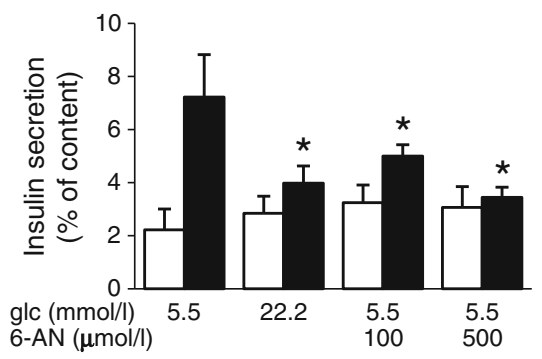

f

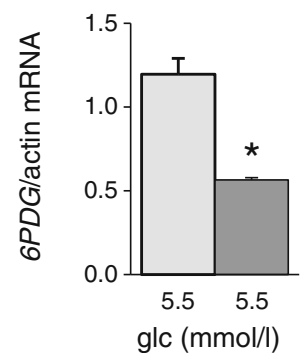

Fig. 3 a, b Insulin mRNA levels significantly decreased during high glucose or 6-AN treatment. INS-1E cells were exposed to 6-AN for $48 \mathrm{~h}$ (a) and human islets for $72 \mathrm{~h}$ (b). mRNA levels are expressed relative to $\beta$-actin. Glucose-stimulated insulin secretion was performed in islets after $72 \mathrm{~h}$ pre-culture with 5.5 or $22.2 \mathrm{mmol} / 1$ glucose or $5.5 \mathrm{mmol} / 1$ glucose in the presence of 100 or $500 \mu \mathrm{mol} / 16-\mathrm{AN}$. Basal and stimulated insulin denote the amount of insulin secreted during $1 \mathrm{~h}$ at 2.8 or $16.7 \mathrm{mmol} / \mathrm{l}$ glucose (basal [white bars] and stimulated [black bars], respectively) and expressed as \% of insulin content. d-f Glucose-stimulated insulin secretion is impaired in 6PGD-depleted human islets. Glucose-stimulated insulin secretion

Exposure to high glucose and inhibition of the PPP activate $E R K 1 / 2$ Glucose-dependent regulation of insulin transcription is dependent on extracellular signal-regulated protein kinases (ERK1/2). Previously, we have demonstrated that ERK1/2 kinase is activated by glucose $[16,17]$ and that this activation requires glucose metabolism [17, 18]. In agreement with this, short-term incubation (up to $1 \mathrm{~h}$ ) of INS-1E cells (ESM Fig. 6a) and human islets (Fig. 4a) with high glucose concentrations led to a robust ERK1/2 phosphorylation, which declined between 2 and $12 \mathrm{~h}$ after initial glucose exposure. Extended exposure to high glucose levels (24 to $72 \mathrm{~h}$ ) again led to significant ERK1/2 activation (Fig. 4a, ESM Fig. 6a).

We speculated that this late ERK1/2 activation may be due to accumulation of metabolites from the PPP as a result of impaired glucose catabolism through the pentose phosphate shunt and that subsequently, insulin expression through ERK1/2 activation may be affected. Indeed, inhibition of 6PGD by 6-AN at low glucose concentrations promoted ERK1/2 phosphorylation to a similar extent as long-term high glucose treatment alone in INS-1 cells was performed in islets $96 \mathrm{~h}$ after transfection with $100 \mathrm{nmol} / 1 \mathrm{si} 6 P G D$ at 5.5 or $22.2 \mathrm{mmol} / \mathrm{l}$ glucose. d Basal and stimulated insulin denote the amount of insulin secreted during $1 \mathrm{~h}$ at 2.8 or $16.7 \mathrm{mmol} / \mathrm{l}$ glucose (basal [white bars] and stimulated [black bars], respectively). e Stimulatory index is given as the ratio of stimulated to basal insulin. f mRNA levels are expressed relative to $\beta$-actin. e, f Light grey bars, scramble siRNA; dark grey bars, si6PGD. Data shown are means $\pm \mathrm{SE}$ from three different experiments (islets and INS-1E) from three different islet isolations. ${ }^{*} p<0.05$ vs $5.5 \mathrm{mmol} / 1$ glucose; ${ }^{\dagger} p<0.05$ vs $22.2 \mathrm{mmol} / 1$ glucose. siScr, scramble siRNA

(ESM Fig. 6b,c) and in human islets (Fig. 4b,c). ERK1/2 phosphorylation was potentiated after $72 \mathrm{~h}$ culture of human islets with 6-AN (Fig. 4b,c).

ERK1/2 inhibition attenuates accumulation of PPP metabolites and improves beta cell function To test whether the PPP metabolite accumulation induced by chronic exposure to glucose is mediated by prolonged ERK activation, we determined PPP metabolites under ERK inhibition. The simultaneous cultivation of INS-1E cells with $16 \mathrm{mmol} / \mathrm{l}$ glucose and the ERK inhibitor PD98059 attenuated the accumulation of glucono- $\delta$-lactone (Fig. 5a), gluconic acid (Fig. 5b) and 6-phosphogluconic acid (Fig. 5c). In comparison with $16 \mathrm{mmol} / \mathrm{l}$ glucose treatment, metabolite levels were reduced by $55 \%, 62 \%$ and $66 \%$, respectively, in the presence of PD98059.

Subsequently, we tested whether ERK1/2 inhibition under chronic glucose exposure may also lead to normalisation of insulin transcription and beta cell function. INS$1 \mathrm{E}$ cells and human islets were cultured for $48 \mathrm{~h}$ in low and high glucose in the presence or absence of PD98059 or 
a

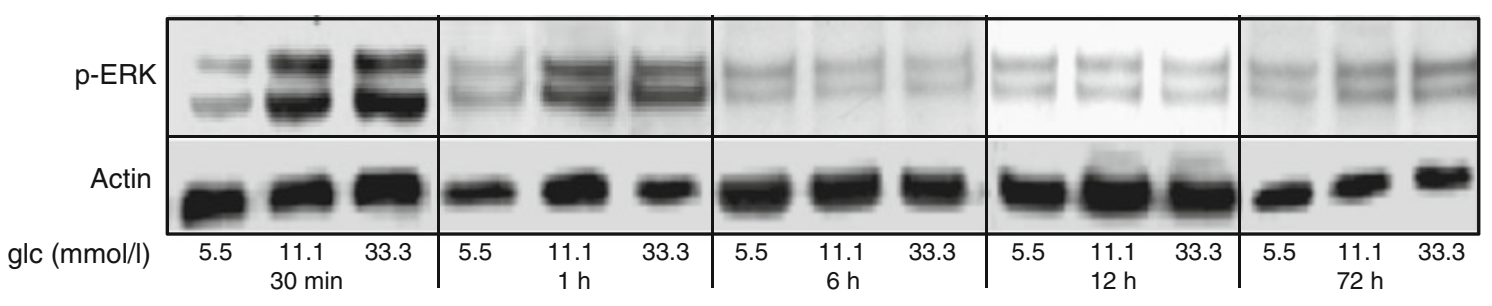

b
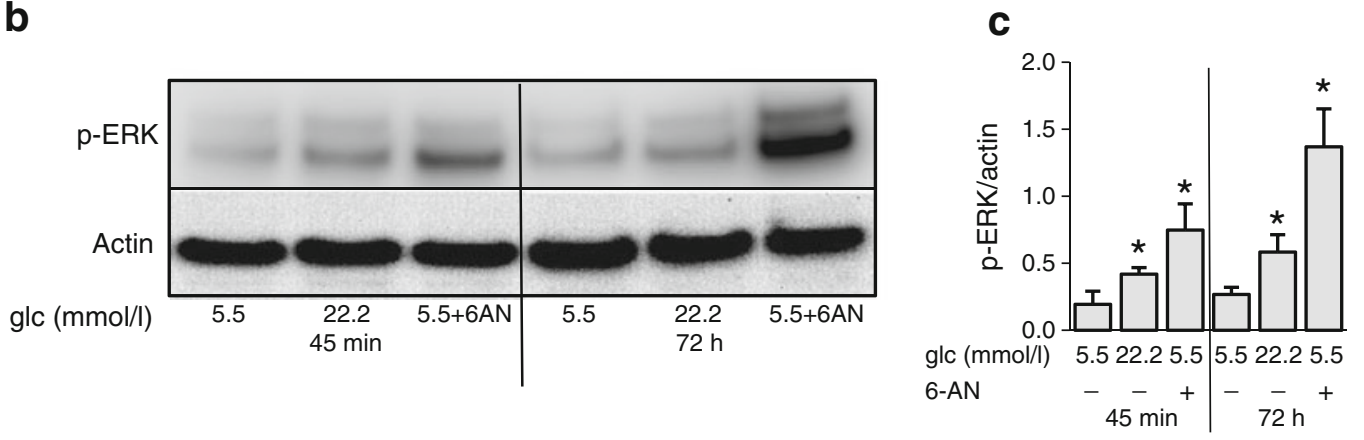

Fig. 4 Increased ERK1/2 activity during acute and chronic high glucose (glc) treatment and after PPP inhibition at low extracellular glucose concentrations. Western blot analyses of p-ERK1/2 of human islets (a) exposed to 5.5, 11.1 and $33.3 \mathrm{mmol} / 1$ glucose during $72 \mathrm{~h}$ culture and (b) cultured at $5.5 \mathrm{mmol} / 1$ glucose $+500 \mu \mathrm{mol} / \mathrm{l} 6-\mathrm{AN}$ for

U0126, specific chemical inhibitors of ERK1/2 [19, 20]. We observed that ERK1/2 inhibition was sufficient to prevent the insulin gene suppression induced by high glucose in both INS-1E cells (Fig. 5d) and human islets (Fig. 5e). This was paralleled by the restoration of MAFA and PDX-1 expression in human islets (Fig. 5e; BETA2 not tested) and a partial restoration of Mafa, Beta 2 and $P d x-1$ in INS-1E cells (Fig. 5d).

To determine whether chronically elevated glucose levels alter insulin secretion in parallel to changes in insulin transcription, human islets were maintained at low and elevated glucose levels for 3 days with or without ERK1/2 inhibitor PD98059 and exposed to an additional short-term high glucose challenge (Fig. 5f,g). While insulin secretion stimulated by acute glucose was enhanced in islets precultured at low glucose, islets chronically exposed to high glucose (11.1 or $33.3 \mathrm{mmol} / \mathrm{l})$ failed to secrete insulin upon additional glucose challenge (Fig. 5f). Western blot analysis confirmed that loss of glucose-stimulated insulin secretion in islets pre-treated with high glucose was paralleled by blunted ERK1/2 phosphorylation (Fig. 5f, blot). Coincubation with the ERK1/2 inhibitor PD98059 during the 3 day culture period followed by glucose stimulation without the inhibitor significantly improved glucoseinduced insulin secretion together with ERK1/2 phosphorylation (Fig. 5g). Similar results were obtained by using U0126 (not shown). Also, protection from beta cell overwork during the glucose incubation by co-culture with
72 h. Representative blots are shown from three organ donors. Densitometry analyses of bands normalised to actin (c), data are mean $\pm \mathrm{SE} ;{ }^{*} p<0.05$ treated vs control condition $(5.5 \mathrm{mmol} / 1$ glucose) at the same exposure time (INS-1E results, see ESM)

diazoxide, a $\mathrm{K}_{\mathrm{ATP}}$-channel opener that inhibited insulin secretion during long-term glucose exposure, restored acute glucose-stimulated insulin secretion together with ERK activation (Fig. 5h). These effects were independent from insulin secretion, as demonstrated by parallel incubation of human islets with somatostatin during chronic and acute glucose exposure (Fig. 5i). Despite unchanged insulin levels, glucose alone was able to induce ERK activation (Fig. 5i, blot). As glucose desensitisation is a temporary state that can be reversed upon restoration of normoglycaemia, we postulated that in parallel to glucose sensing, islets would also regain the ability to respond to glucose by activating ERK1/2. To test this hypothesis, islets chronically incubated at $5.5,11.1$ or $33.3 \mathrm{mmol} / 1$ glucose were cultured for another 2 days at $5.5 \mathrm{mmol} / \mathrm{l}$ glucose to allow recovery from chronic hyperglycaemia before acute glucose stimulation (Fig. 5j). The recovery period restored acute enhanced insulin secretion and ERK1/2 phosphorylation in islets previously treated with $11.1 \mathrm{mmol} / 1$ glucose for 3 days. In contrast, at chronic culture with $33.3 \mathrm{mmol} / \mathrm{l}$ glucose, normoglycaemia failed to reverse the effects of glucose and neither insulin secretion (Fig. 5j, graph) nor ERK1/2 phosphorylation (Fig. 5j, blot) was re-induced in those islets in response to acute glucose challenge. These data demonstrate that in addition to culture time, glucose concentration also plays a crucial role in the ability of beta cells to recover from hyperglycaemia-induced impaired beta cell function. 
Fig. 5 ERK1/2 inhibition alters PPP metabolite levels and improves beta cell function. a-c INS-1E cells were cultured at $3 \mathrm{mmol} / 1,16 \mathrm{mmol} / 1$ and $16 \mathrm{mmol} / \mathrm{l}$ glucose $(\mathrm{glc})+$ PD98059 (PD) for 48 h. Intracellular metabolites gluconic acid- $\delta$-lactone (a), gluconic acid (b) and 6-phosphogluconic acid (c) were measured with GC-TOF-MS. d,e Insulin mRNA and mRNA of islet transcription factors from INS-1E cultured for $48 \mathrm{~h}$ at $3 \mathrm{mmol} / \mathrm{l}$ glucose (white bars), $16 \mathrm{mmol} / \mathrm{l}$ glucose (black bars) and $16 \mathrm{mmol} / \mathrm{l}$ glucose + PD98059 (grey bars) (d) and from isolated human islets cultured for $72 \mathrm{~h}$ at $5.5 \mathrm{mmol} / 1$ (white bars) or $22.2 \mathrm{mmol} / 1$ (black bars) glucose or $22.2 \mathrm{mmol} / \mathrm{l}$ glucose+PD98059 (grey bars) (e). Quantitative RT-PCR analysis shows mean expression levels normalised to control (low glucose) and to actin and tubulin with the same result. (f-j) Following a chronic 3 day culture of human islets at 5.5, 11.1 or $33.3 \mathrm{mmol} / 1$ glucose with $(\mathbf{g}-\mathbf{i})$ or without (f, control) additional treatment, glucose-stimulated insulin secretion and ERK phosphorylation in human islets were assessed after additional culture for $1 \mathrm{~h}$ at either 5.5 or $33.3 \mathrm{mmol} / 1$ glucose. During the 3 day culture period, human islets were treated with $10 \mu \mathrm{mol} / 1$ PD98059 (ERKinhibitor) (g), $200 \mu \mathrm{mol} / \mathrm{l}$ diazoxide

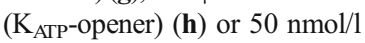
somatostatin (inhibition of insulin secretion) (i). Somatostatin was also included during the acute glucose stimulation (i). In (j), islets were treated after the 3 day culture period for another 2 days at $5.5 \mathrm{mmol} / \mathrm{l}$ (recovery period) and then stimulated. Data shown are means \pm SE from five $(\mathbf{a} ; \mathbf{f}-\mathbf{j})$ or three (d,e) different experiments (INS-1E and islets) from five or three different islet donors. ${ }^{*} p<0.05$ high glucose compared with low glucose; ${ }^{\dagger} p<0.05$ treated vs untreated at same glucose concentration; ${ }^{\star} p<0.05$ stimulated vs basal insulin secretion. f-h White bars, basal; black bars, stimulated; $\mathbf{g}$ black bars, stimulated + somatostatin

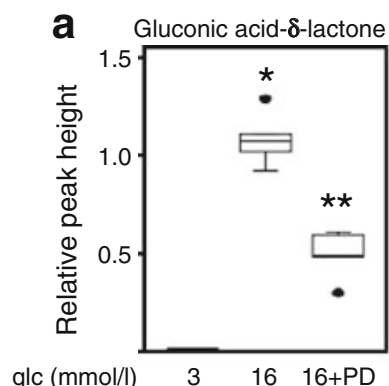

d

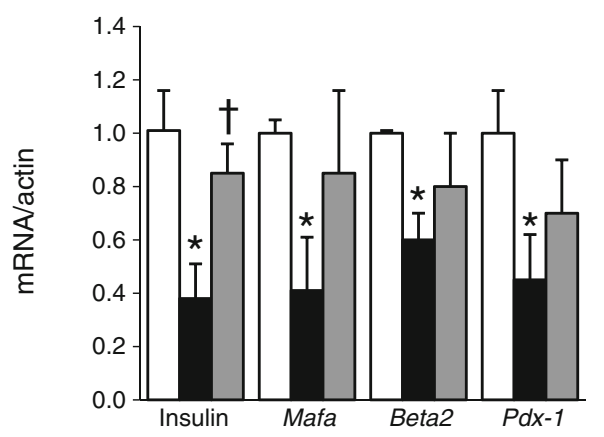

f

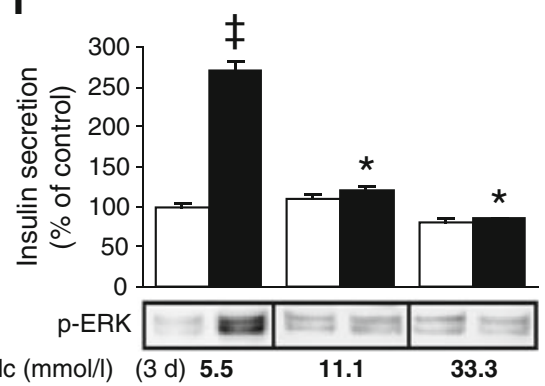

h

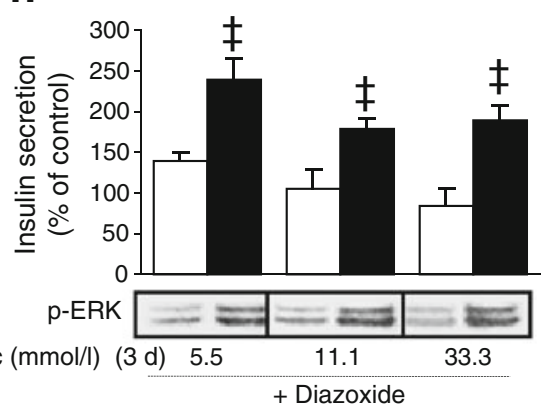

j

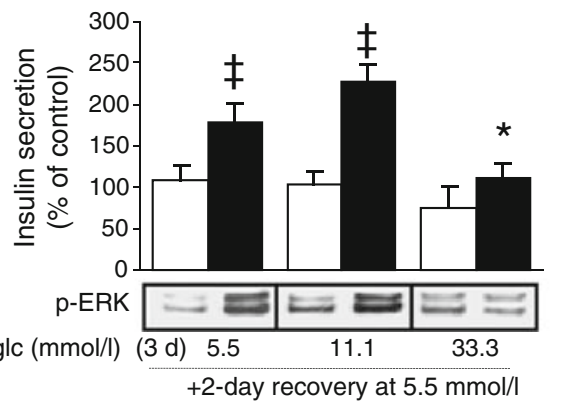

C 6-Phosphogluconic acid
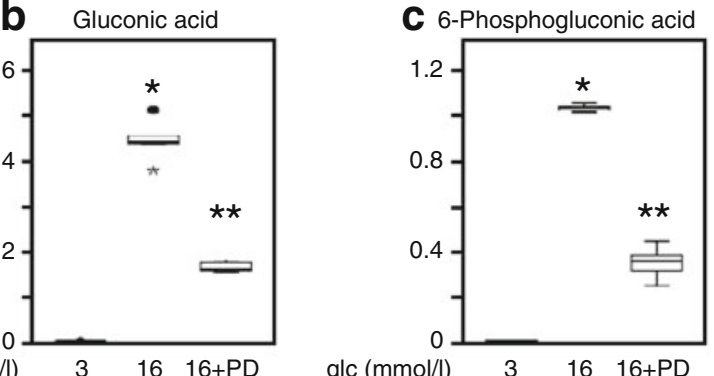

e
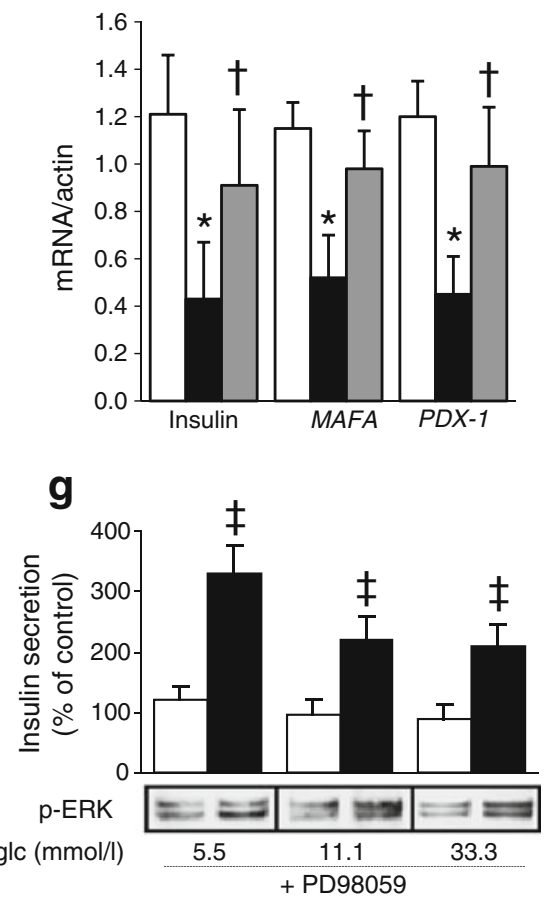

i

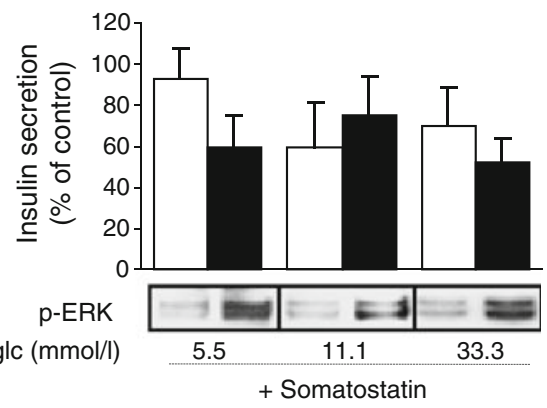




\section{Discussion}

We report that metabolites from the PPP accumulate in pancreatic beta cells during chronic exposure to high glucose and suggest that impaired processing of glucose through the PPP is involved in insulin gene suppression in an ERK1/2-dependent fashion.

Chronically elevated glucose impairs beta cell function and insulin expression [1, 2]. This indicates glucose metabolism in the beta cell and suggests that specific glucose-derived intracellular metabolites may act as second messengers linking glucose metabolism and insulin expression and secretion. Using an unbiased approach we aimed to identify intracellular metabolites affecting beta cell function. A mass spectroscopic screen of 73 metabolites was performed where three PPP metabolites were found to account for the vast majority of the variance in the data following acute and chronic increases in glucose and suggests that those PPP metabolites may mediate glucoseinduced impairment of the beta cell.

The unbiased analysis demonstrates association, but does not per se demonstrate causality. Such a mechanistic link is provided by experiments using the 6-phosphogluconic acid dehydrogenase inhibitor 6-AN, which caused an increase in PPP metabolites and a decrease in insulin gene transcription, mimicking chronic high glucose treatment. Those data support that the accumulation of PPP metabolites alone is sufficient to impair beta cell function.

Physiologically, the contribution of the PPP in glucose utilisation is very limited. After acute stimulation, the beta cell mainly metabolises glucose through glycolysis, and only a small portion enters the pentose phosphate shunt [21]. Almost $100 \%$ of the total glucose used is for oxidative $\mathrm{CO}_{2}$ production [22]. Increased NADPH production by the PPP itself and through the Krebs cycle pyruvate/malate shuttle [23] would inhibit glucose-6-phosphate dehydrogenase, the 'switch-on' enzyme of the PPP. The PPP correlates with neither $\mathrm{CO}_{2}$ formation nor with insulin release [22]. Glucose use through the PPP under pathophysiological conditions, such as glucotoxicity, may however be altered and should be investigated in more detail. We hypothesise that during glucotoxicity, an increased demand for NADPH and in turn consumption by NADPH-requiring processes may explain why a portion of glucose is still metabolised in the PPP and metabolites accumulate with a negative effect on insulin secretion. As a result of chronic high glucose exposure and hyperglycaemia NADPH-requiring metabolic pathways such as sorbitol synthesis [24] and fatty acid synthesis are activated. Increased levels of sorbitol have been measured in the present study and an increase in lipogenesis and fatty acid synthase mRNA levels has been reported [25]. Other NADPH-requiring pathways, including biosynthesis and catabolism of proteins, cholesterol and pyrimidine synthesis could be increased and increased carbamyl-aspartic has been reported in the present study. Even though still hypothetical, an increased demand for NADPH during glucotoxicity may explain why a portion of glucose is still metabolised in the PPP. The detected accumulation of the PPP metabolites may, however, not necessarily be a result of increased glucose flux through the PPP, but rather due to relative insufficient 6-PGD enzyme activity apparent during long-term elevated glucose. Our data show that $6-P G D$ deletion results in impaired beta cell function, a finding in favour of such speculation; however, in contrast, the protein and mRNA levels of the enzyme remain unchanged following chronic high glucose exposure, thereby indicating that enzyme synthesis is not impaired. We suggest that the enzyme activity of the enzyme is negatively regulated, but by which factors remains to be investigated.

Besides regulation of insulin secretion by the TCA cycle [26], the concept that the pentose phosphate shunt plays a role in glucose-induced insulin secretion was established over 40 years ago [27-30], but its involvement during the switch from glucose-induced insulin secretion to impaired function has not been identified. Ammon et al. showed that 6-AN at a comparable concentration as used in this study reduces insulin mRNA in isolated rat islets when injected i. p. before isolation, but $24 \mathrm{~h}$ incubation of islets in vitro has no effect on insulin mRNA [30]. In our study, robust changes in insulin mRNA could only be detected after long-term stimulation; reduction in insulin mRNA levels in human islets were shown only after $72 \mathrm{~h}$. In line with this, 6-AN also reduced insulin mRNA after $48 \mathrm{~h}$, indicating that only extended metabolite accumulation affects insulin mRNA levels. Increased chronic 6-AN effects were also observed at the level of ERK activation. After $72 \mathrm{~h}$ exposure of human islets to 6-AN, ERK was further increased when compared with an acute exposure of $45 \mathrm{~min}$. The mechanisms of this glucose switch may therefore be that acute-glucose-induced ERK activation and insulin secretion occurs partially through PPP metabolism but during glucotoxicity, massive accumulation of PPP metabolites result in prolonged ERK activity; this, in turn, enhances metabolite accumulation and finally affects insulin mRNA production.

ERK $1 / 2$ is a common pathway of acute glucose signalling in the beta cell, which directly links to insulin secretion [31], but prolonged ERK1/2 activation fosters impairment in beta cell function and beta cell apoptosis [16]. The addition of ERK1/2 inhibitors (PD98059 or U0126) during chronic high-glucose incubation prevented the observed decrease in insulin transcription and attenuated accumulation of metabolites of the PPP. The two inhibitors of ERK1/2 had similar effects on glucose-stimulated insulin secretion. Inhibitory effects independent of the MAP kinase pathway were reported in the past. 
Both PD98059 and U0126 affect the cellular AMP/ATP ratio, which could lead to an activation of AMPK and a complete reset of the metabolic state of the cell after exposure to these inhibitors [32]. Glutathione levels in rat hepatocytes are elevated by PD98059 independent of the inhibition of MEK, the inactive form of mitogen-activated protein kinase (MAPK) [33]. We cannot exclude that such indirect effects modulated the measured metabolites. But, as ERK inhibition by PD98059 reduced PPP accumulation and vice versa-6-AN induced PPP accumulation and activated ERK-we can assume a specific ERK inhibition in this experimental model.

Because of physiological effects of ERK and its important role in the beta cell for glucose-stimulated insulin secretion, inhibition of ERK as a generalised therapy for diabetes is not desirable. In contrast, specific activators of PPP enzymes, e.g. activators of the 6PGD, could be novel targets for therapy. Such a possibility is currently under investigation in our laboratory.

Prolonged ERK1/2 activation induced a resistance to glucose-induced ERK1/2 activation and thus prevented further ERK1/2 activation as well as insulin secretion in response to glucose. As PPP metabolites also accumulate independently of glucose, it can be speculated that ERK1/2 activation may be triggered by: the metabolites themselves; interference of these metabolites with other metabolic pathways; or an abnormal cytosolic redox state. Different PPP metabolites are potent inhibitors of phosphoglucose isomerase [34-36]. The inhibition of phosphoglucose isomerase would consequently prevent glucose turnover in glycolysis. Impediment of glycolysis would explain why stimulatory glucose concentrations in islets after prolonged exposure to high glucose remain ineffective to mobilise insulin release. Contrary to this, inhibition of the ERK1/2 pathway attenuates accumulation of PPP metabolites, suggesting that ERK1/2 itself may be involved in the regulation and the pentose phosphate shunt (see ESM Fig. 7).

Whether glucotoxicity occurs after those metabolites simply cross a certain concentration threshold or after being elevated for a prolonged period remains to be determined. As beta cell failure results from interplay of many different factors, it is possible that such accumulation is induced secondary to other known mediators of glucotoxicity, such as post-translational modifications, oxidative damage, endoplasmic reticulum stress, which particularly contribute to the observed effects on insulin expression or secretion. At present, little is known about ERK1/2 phosphorylation by intracellular molecules in pancreatic beta cells. In other cell types intracellular ROS generation inhibits ERK1/2-directed phosphatase activity [37] resulting in sustained ERK1/2 activation. An impairment of the oxidative portion of the PPP might be crucial, as the PPP provides a mature portion of the cells' NADPH at a very early stage of glucose metabolism. NADPH provides reducing equivalents for the regeneration of reduced glutathione, which serves a protective role against ROS formation. Exposure of cells to chronic high glucose results in increased ROS production; glutathione peroxidase plays a crucial role in protection against oxidative stress [38] and is present at low levels in the beta cell even under non-glucotoxic conditions [39]. PPP metabolite accumulation would suggest that NADPH is abundant. NADPH inhibits glucose-6-phosphate dehydrogenase [28]. Further conversion of glucose to gluconolactone would then be inhibited and not result in increased levels of the PPP metabolites. This explains why an increased glucose concentration during acute stimulation inhibits processing of glucose through the PPP [22].

It is unquestionable that the analysis presented here does not uncover all existing links between glucose metabolism and beta cell dysfunction. Many well-established signals in insulin secretion, specifically those contributing to the cellular redox state such as ATP/ADP, NADP/NADHP and NAD/NADH, were not studied, despite substantial evidence that they contribute to the regulation of beta cell function [11]. Our data do not exclude the contribution of such additional pathways, but strongly suggest that the isolated accumulation of PPP metabolites is sufficient to induce beta cell dysfunction.

In conclusion, our data demonstrate that PPP metabolites accumulate during long-term exposure to high glucose concentrations and may act as secondary messengers activating ERK1/2 and contribute to the inhibition of beta cell function. The insights presented here may provide novel perspectives in the therapeutic goal to preserve and potentially improve the beta cell.

Acknowledgements We thank A. Eckardt for assistance in measuring metabolites and N. Huckauf and J. Bergemann for excellent technical assistance. Part of the work was performed in H. Mulder's research group, Malmö, Sweden, and we would like to thank him for providing the material needed. This work was supported by a Heisenberg-Professorship (SP716/2-1), a Clinical Research Group (KFO218/1), the DFG-Emmy Noether Programme (MA4172/1-1), the ERC, a research group (Molecular Nutrition) of the Bundesministerium für Bildung und Forschung (BMBF) and by the Juvenile Diabetes Research Foundation (JDRF). Human islets were provided through the Islet Cell Resource Consortium, administered by the Administrative and Bioinformatics Coordinating Center (ABCC) and supported by the National Center for Research Resources (NCRR), the National Institute of Diabetes and Digestive and Kidney Diseases (NIDDK) and the JDRF. INS-1E cells were kindly provided by C. B. Wollheim, Geneva, Switzerland.

Contribution statement Conception and design, IG, NSS, GC, MM, AFHP, LW, JS, KM; analysis and interpretation of data, IG, NSS, AA, LS, KSZ, JO, JS, KM; drafting the article, IG, NSS, JS, KM; critical revision of the article, IG, NSS, GC, AA, LS, KSZ, MM, AFHP, JO, LW, JS, KM; all authors gave final approval of the version to be published.

Duality of interest The authors declare that there is no duality of interest associated with this manuscript. 


\section{References}

1. Leahy JL, Cooper HE, Deal DA, Weir GC (1986) Chronic hyperglycemia is associated with impaired glucose influence on insulin secretion. A study in normal rats using chronic in vivo glucose infusions. J Clin Invest 77:908-915

2. Robertson RP (1989) Type II diabetes, glucose "non-sense," and islet desensitization. Diabetes 38:1501-1505

3. Jonas JC, Sharma A, Hasenkamp W et al (1999) Chronic hyperglycemia triggers loss of pancreatic beta cell differentiation in an animal model of diabetes. J Biol Chem 274:14112-14121

4. Poitout V, Robertson RP (2008) Glucolipotoxicity: fuel excess and beta-cell dysfunction. Endocr Rev 29:351-366

5. Maedler K, Sergeev P, Ris F et al (2002) Glucose-induced betacell production of interleukin-1beta contributes to glucotoxicity in human pancreatic islets. J Clin Invest 110:851-860

6. Donath MY, Boni-Schnetzler M, Ellingsgaard H, Ehses JA (2009) Islet inflammation impairs the pancreatic beta-cell in type 2 diabetes. Physiology (Bethesda) 24:325-331

7. Evans-Molina C, Garmey JC, Ketchum R et al (2007) Glucose regulation of insulin gene transcription and pre-mRNA processing in human islets. Diabetes 56:827-835

8. Oberholzer J, Triponez F, Mage R, Andereggen E, Buhler L et al (2000) Human islet transplantation: lessons from 13 autologous and 13 allogeneic transplantations. Transplantation 69:1115-1123

9. Asfari M, Janjic D, Meda P et al (1992) Establishment of 2mercaptoethanol-dependent differentiated insulin-secreting cell lines. Endocrinology 130:167-178

10. Ardestani A, Sauter NS, Paroni F et al (2011) Neutralizing interleukin-1 $\beta$ (IL-1 $\beta$ ) induces $\beta$-cell survival by maintaining PDX1 protein nuclear localization. J Biol Chem 286:17144-17155

11. Fernandez C, Fransson U, Hallgard E et al (2008) Metabolomic and proteomic analysis of a clonal insulin-producing beta-cell line (INS-1 832/13). J Proteome Res 7:400-411

12. Dietrich LS, Friedland IM, Kaplan LA (1958) Pyridine nucleotide metabolism: mechanism of action of the niacin antagonist, 6aminonicotinamide. J Biol Chem 233:964-968

13. Johnson WJ, McColl JD (1955) 6-Aminonicotinamide-a potent nicotinamide antagonist. Science 122:834

14. Kolbe H, Keller K, Lange K, Herken H (1977) Glucose metabolism in C-1300 neuroblastoma cells after inhibition of hexose monophosphate pathway. Naunyn Schmiedebergs Arch Pharmacol 296:123-130

15. Meyer-Estorf G, Schulze PE, Herken H (1973) Distribution of ${ }^{3} \mathrm{H}$-labelled 6-aminonicotinamide and accumulation of 6phosphogluconate in the spinal cord. Naunyn Schmiedebergs Arch Pharmacol 276:235-241

16. Maedler K, Storling J, Sturis J, Zuellig RA, Spinas GA et al (2004) Glucose- and interleukin-1beta-induced beta-cell apoptosis requires $\mathrm{Ca}^{2+}$ influx and extracellular signal-regulated kinase (ERK) $1 / 2$ activation and is prevented by a sulfonylurea receptor 1/inwardly rectifying $\mathrm{K}^{+}$channel 6.2 (SUR/Kir6.2) selective potassium channel opener in human islets. Diabetes 53:17061713

17. Assmann A, Ueki K, Winnay JN, Kadowaki T, Kulkarni RN (2009) Glucose effects on beta-cell growth and survival require activation of insulin receptors and insulin receptor substrate 2 . Mol Cell Biol 29:3219-3228

18. Khoo S, Cobb MH (1997) Activation of mitogen-activating protein kinase by glucose is not required for insulin secretion. Proc Natl Acad Sci USA 94:5599-5604

19. Alessi DR, Cuenda A, Cohen P, Dudley DT, Saltiel AR (1995) PD 098059 is a specific inhibitor of the activation of mitogenactivated protein kinase kinase in vitro and in vivo. $\mathrm{J}$ Biol Chem 270:27489-27494
20. Favata MF, Horiuchi KY, Manos EJ, Daulerio AJ, Stradley DA et al (1998) Identification of a novel inhibitor of mitogen-activated protein kinase kinase. J Biol Chem 273:18623-18632

21. Snyder PJ, Kashket S, O'Sullivan JB (1970) Pentose cycle in isolated islets during glucose-stimulated insulin release. Am J Physiol 219:876-880

22. Schuit F, de Vos A, Farfari S, Moens K, Pipeleers D et al (1997) Metabolic fate of glucose in purified islet cells. Glucose-regulated anaplerosis in beta cells. J Biol Chem 272:18572-18579

23. MacDonald MJ (1995) Feasibility of a mitochondrial pyruvate malate shuttle in pancreatic islets. Further implication of cytosolic NADPH in insulin secretion. J Biol Chem 270:20051-20058

24. Brownlee M (2001) Biochemistry and molecular cell biology of diabetic complications. Nature 414:813-820

25. Roche E, Farfari S, Witters LA, Assimacopoulos-Jeannet F, Thumelin $\mathrm{S}$ et al (1998) Long-term exposure of beta-INS cells to high glucose concentrations increases anaplerosis, lipogenesis, and lipogenic gene expression. Diabetes 47:1086-1094

26. Maechler P, Kennedy ED, Pozzan T, Wollheim CB (1997) Mitochondrial activation directly triggers the exocytosis of insulin in permeabilized pancreatic beta-cells. EMBO J 16:3833-3841

27. Montague W, Taylor KW (1969) Islet-cell metabolism during insulin release. Effects of glucose, citrate, octanoate, tolbutamide, glucagon and theophylline. Biochem J 115:257-262

28. Ashcroft SJ, Randle PJ (1970) Enzymes of glucose metabolism in normal mouse pancreatic islets. Biochem J 119:5-15

29. Matschinsky FM, Kauffman FC, Ellerman JE (1968) Effect of hyperglycemia on the hexose monophosphate shunt in islets of Langerhans. Diabetes 17:475-480

30. Ammon HP, Patel TN, Steinke J (1973) The role of the pentose phosphate shunt in glucose induced insulin release: in vitro studies with 6-aminonicotinamide, methylene blue, $\mathrm{NAD}^{+}, \mathrm{NADH}$, $\mathrm{NADP}^{+}, \mathrm{NADPH}$ and nicotinamide on isolated pancreatic rat islets. Biochim Biophys Acta 297:352-367

31. Longuet C, Broca C, Costes S, Hani EH, Bataille D et al (2005) Extracellularly regulated kinases 1/2 (p44/42 mitogen-activated protein kinases) phosphorylate synapsin I and regulate insulin secretion in the MIN6 beta-cell line and islets of Langerhans. Endocrinology 146:643-654

32. Dokladda K, Green KA, Pan DA, Hardie DG (2005) PD98059 and U0126 activate AMP-activated protein kinase by increasing the cellular AMP:ATP ratio and not via inhibition of the MAP kinase pathway. FEBS Lett 579:236-240

33. Kim SK, Abdelmegeed MA, Novak RF (2006) The mitogenactivated protein kinase kinase (mek) inhibitor PD98059 elevates primary cultured rat hepatocyte glutathione levels independent of inhibiting mek. Drug Metab Dispos 34:683-689

34. Gumaa KA, McLean P (1969) The pentose phosphate pathway of glucose metabolism. Enzyme profiles and transient and steadystate content of intermediates of alternative pathways of glucose metabolism in Krebs ascites cells. Biochem J 115:1009-1029

35. Parr CW (1956) Inhibition of phosphoglucose isomerase. Nature 178:1401

36. Venkataraman R, Racker E (1961) Mechanism of action of transaldolase. I. Crystalization and properties of yeast enzyme. J Biol Chem 236:1876-1882

37. Traore K, Sharma R, Thimmulappa RK, Watson WH, Biswal S et al (2008) Redox-regulation of Erk1/2-directed phosphatase by reactive oxygen species: role in signaling TPA-induced growth arrest in ML-1 cells. J Cell Physiol 216:276-285

38. Robertson RP, Harmon JS (2007) Pancreatic islet beta-cell and oxidative stress: the importance of glutathione peroxidase. FEBS Lett 581:3743-3748

39. Tiedge M, Lortz S, Drinkgern J, Lenzen S (1997) Relation between antioxidant enzyme gene expression and antioxidative defense status of insulin-producing cells. Diabetes 46:1733-1742 